\title{
Biblioteca Pública e Educação: apontamentos sobre o papel da leitura hoje
}

\author{
Maria da Conceição Carvalho
}

\begin{abstract}
Doutora em Estudos Literários pela Universidade Federal de Minas Gerais. Professora Adjunta da Escola de Ciência da Informação - ECI/UFMG.
\end{abstract}

http://dx.doi.org/10.1590/1981-5344/2285

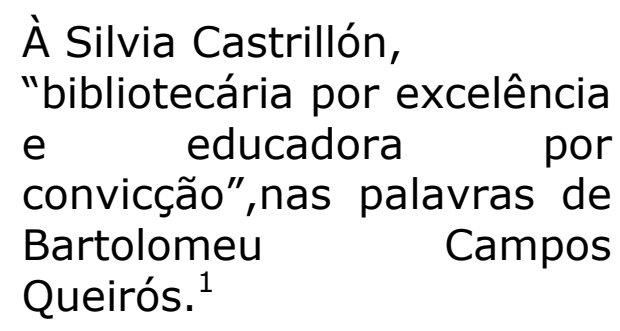

Este artigo propõe algumas reflexões sobre o papel da biblioteca pública e da educação brasileiras hoje, no que se refere à formação de leitores. Essa é uma questão que continua atual e relevante, tendo em vista duas realidades de difícil interrelação: a permanência de altos índices de analfabetismo e iletrismo no país e as novas maneiras de ler e se comunicar que vieram com a revolução digital. O papel do mediador da leitura é também questionado neste artigo.

Palavras-chave: Biblioteca pública. Promoção da leitura. Mediação da leitura.

\section{Public Library and aducation: notes on the role of the library today}

This article offers some thoughts on the role of the public library and the brazilian education today, regarding the formation of readers. This is an issue that continues being current and relevant, bearing in mind two realities of difficult interrelationship: the permanence of high levels of illiteracy in Brazil and the new ways of reading and communicating that came with the digital revolution. The

1 Prefácio da obra: CASTRILLÓN, Silvia. O direito de ler e escrever. São Paulo: Pulo do Gato, 2012. 
role of the mediator of reading is also discussed in this paper.

Key words: Public Library. Reading promotion. Reading mediation.

Recebido em 25.11.2014 Aceito em 26.11.2014

\section{Introdução}

O tema da leitura é algo tão simples, e ao mesmo tempo tão complexo, que é possível falar dele como coisa corriqueira, numa frase despretensiosa, emanada do senso comum, como também pode-se levar longuíssimo tempo tentando entende-la nas suas múltiplas acepções e aplicações. Apresentada pelo crítico literário paulista Davi Arrigucci, já não me lembro exatamente quando, em palestra intitulada Leitura: entre o fascínio e o pensamento, tal proposição, pela força da memória involuntária, se impôs ao movimento dos meus dedos no ato de escrever este texto. Assim, ainda sem decidir qual abordagem privilegiar para a discussão de um tema tão difuso quanto o da LEITURA, deixei que algumas perguntas afluíssem livremente: Como a Biblioteca Pública e a Escolas brasileiras vêm trabalhando a leitura, sabendo-se que a média da população ainda lê tão pouco? Ou: Cabe à biblioteca pública brasileira assumir $\mathrm{m}$ papel mais propositivo em relação à promoção da leitura? Ou ainda: O que muda e o que permanece na Pedagogia da Leitura hoje, na chamada sociedade da informação?

Tais perguntas, não obstante o amplo espectro de questões nelas subentendidas podem abrir o caminho para uma discussão entre pessoas interessadas em participar da construção de uma sociedade menos desigual, na qual a educação e a leitura sejam direito de todos, e que é, certamente, a proposta desse Seminário.

\section{Pensar a leitura hoje}

Retornando ao enunciado de Arrigucci, penso que formulações sobre a leitura, ingênuas ou comprometidas com os grupos hegemônicos, podem ser capciosas e, ao mesmo tempo, inúteis para transformar 0 estado de semi-educação sobre o qual falava Adorno nos meados do século XX (ADORNO, 1999) e que ainda retrata, em certa medida, o panorama geral da educação no país. De fato, a questão da leitura, via de regra, é mostrada ao grande público ora na visão do mercado, satisfeito em divulgar números altíssimos de determinados livros vendidos, sem levar em consideração que livro vendido não significa, em verdade, livro lido, sobretudo em épocas de Feiras e Bienais, quando mesmo quem lê pouco ou não lê de fato, se impressiona com o grande alarido que se faz em torno de alguns autores e títulos da moda; em outros momentos o que sobressai é, ainda, a visão alinhada com os teóricos que Umberto Eco 
chamou, nos anos 70 do século passado, de apocalípticos, visão que ressalta a crise da leitura e (pre)vê a ampliação numérica do leitor fraco,aquele que lê de zero a quatro livros por ano, e que, na análise da filóloga e educadora espanhola Teresa Colomer (2007, p. 50-51), pensando especificamente o jovem leitor no contexto da escola, faz leituras parciais e casuais, escolhe sobretudo autores não legitimados e obras que exigem pouca concentração, não se lembrando nem do nome do escritor nem do título do livro. ${ }^{2}$ Embora a complexidade da cultura mundializada esteja a exigir mudanças paradigmáticas que permitam compreendê-la no cenário social e político que hoje se apresenta, o sentimento adorniano, recusado em parte por Eco, talvez não seja totalmente inapropriado para estes tempos de comunicação instantânea que desmerece a reflexão, de predomínio da palavra abreviada e de textos fragmentados, comportamentos que parecem cada vez mais distantes da leitura crítica,pelo menos do modo de ler como o compreendíamos antes da revolução digital.

Certamente, sabemos que há questões mal avaliadas e precariamente resolvidas relativas à leitura e à formação de leitores no Brasil que solicitam a atenção de todos nós, educadores e bibliotecários. De fato, neste começo do terceiro milênio, em que, por um lado, as aceleradas transformações das tecnologias da informação e comunicação nos surpreendem com possibilidades nunca antes imaginadas de ter diante de nós, com um simples toque na tela(em breve, quem sabe, com um simples comando de voz) todo o acervo universal de conhecimentos já formulados e registrados pelo homem desde a antiguidade até agora, e que, na visão otimista dos tecnófilos, já estaria ao alcance de todos, sem distinção de renda e de nível educacional! Entretanto, esse paraíso ainda não nos foi desvelado! Diante de nós apresenta-se a extrema desigualdade social e cultural entre brasileiros das diferentes classes, desigualdade que tem se mostrado cada vez mais assustadora e injusta, que tem servido de estopim para a violência urbana e rural e levado multidões às ruas para reivindicar, entre outras questões fundamentais, Educação e Informação de qualidade, acessíveis a todos os cidadãos do nosso país.

Como associar, então, a leitura à questão central desse Seminário, ou seja, a atuação política da biblioteca pública num mundo em processo acelerado de transformação? Com maior ou menor capacidade crítica, quantos de nós, envolvidos na transmissão do conhecimento como fator de transformação individual e social, continuamos presos à herança da tradição iluminista e acreditamos na leitura em geral, como instrumento de formação e aprimoramento, não apenas da criança e do jovem, ligados a sistemas formais e informais de educação, como também do adulto, em

\footnotetext{
${ }^{2}$ Pesquisas francesas de Sociologia da leitura classificam os leitores em fracos (lêem de zero a quatro livros por ano), médios (lêem cinco a nove livros) e fortes (lêem mais de dez livros) COLOMER, Teresa. Andar entre
} livros. São Paulo: Gobal, 2007. p. 50. 
processo de educação continuada. De fato, seria quase natural essa crença inabalável na leitura como motor de transformação e enriquecimento, na dimensão individual, social, cultural, não fosse, vejam a contradição, essa mesma crença estar, no Brasil, frequentemente desvinculada de experiências concretas de leitura. Como isso se dá? 0 exemplo mais corriqueiro dessa dissociação nos é dado por aquelas pessoas que, mesmo sem gostar de ler, possuem livros de belas encadernações como fonte de distinção social! Contudo, a história brasileira é uma fonte riquíssima de outros exemplos dessa defasagem entre a crença no valor da leitura e no estudo formal e a prática efetiva desses atos na vida cotidiana. Ezequiel Theodoro da Silva, professor e pesquisador da leitura expressa bem essa situação quando diz que no Brasil ainda vigora um ensino livresco ... sem livros!

Vale, ainda, observar, inspirados pela reflexão de Paulo Freire sobre a pedagogia do oprimido (FREIRE, 1988), como essa crença cega no valor da Escola e do Saber se apresenta não apenas na expectativa ingênua de ascensão social das classes subalternas, como no discurso muitas vezes mal conformado do profissional bibliotecário e do professor, como também, nos textos que informam os documentos oficiais de políticas públicas de leitura. Uma pesquisa americana dos anos 80 (ROSS, 1987) destaca, entre as ideias mais usadas pelas entidades públicas e privadas para incentivar o gosto pela leitura as metáforas da escada e do ato de comer! A escada, obviamente, sugere a ligação entre 0 ato de ler e a possibilidade de "subir na vida" e o ato de se alimentar exprime, simbolicamente, a (boa) nutrição cultural. Poderíamos acrescentar a metáfora da viagem, largamente usada pela publicidade brasileira de livros, ou da ponte, ou da janela para o mundo, entre tantas outras. Quem nunca ouviu, leu ou usou expressões como: "Ler é viajar"; "Adorei o livro X, devorei-o em poucas horas..."; "Fulana começou lendo Sabrina e em pouco tempo galgou os mais altos degraus da literatura universal". Usadas para criar ou reforçar a crença no valor social da leitura e a predisposição para ler, aquelas metáforas querem passar a ideia de libertação, travessia, nutrição, ascensão, apontando, claramente, para uma hierarquia de valores que, supostamente, se alcança através da educação escolar e da leitura. Ou, em outras palavras: ler, nessas falas, significa ascender acima daqueles que não lêem, embora não se leve em conta, nessa crença, a qualidade do texto lido (leia qualquer coisa, mas leia, é um mote que se ouve com frequência) e o efeito dessa leitura no indivíduo que lê. Também não se pensa nas condições preexistentes fundamentais para que alguém se torne leitor como, entre outras, família leitora e/ou formação escolar, condições financeiras mínimas para comprar livros e frequentar bibliotecas, disponibilidade de tempo, ou, ainda, a oferta de material de leitura no espaço social de cada um (existência de bibliotecas públicas, de livrarias, o acesso/posse a/de computadores).

\section{Mediação de leitura}


Como leitora que sou, acredito, sim, no potencial da leitura como libertação, travessia e como possibilidade de transformação. Mas, como professora em uma escola de formação de bibliotecários, que serão amanhã formadores de leitores, tenho que desconfiar de uma pregação vazia sobre o poder da leitura, qualquer leitura, propaganda que "oculta mostrando", para usar as palavras de Bourdieu ao referir-se àtelevisão como instrumento de violência simbólica (BOURDIEU, 1997).O discurso de prescrição (terminologia freireana) sobre o valor do livro e da leitura, reproduzido por professores e bibliotecários, se efetiva na indicação simplificada do remédio da salvação - a leitura - sem considerar convenientemente o risco dos efeitos colaterais da leitura de reprodução, a que proporciona ao leitor não mais que a (falsa) sensação de estar informado. O grande risco relativo à predominância desse tipo de mediação é que mantem-se, assim, inalterada, a grande distância entre os brasileiros que efetivamente lêem e podem praticar uma leitura de emancipação, e os que apenas enxergam a leitura como algo a ser buscado como sinal de distinção social,não dispondo, entretanto, de reais condições para estabelecer uma experiência metódica e consistente com a leitura, que leve, efetivamente à construção de novos sentidos.

Acredito, ainda, que professores e bibliotecários, no seu cotidiano profissional, precisam levar em conta as especificidades e complexidades que permitem a uma pessoa tornar-se ou não tornar-se leitor, atentos que devem estar às condições reais da sociedade brasileira nesse início de século, refletindo com seriedade sobre os componentes sócioculturais que estariam na raiz da suposta falta de vontade de ler do nosso povo. A distância entre o estado de não leitor para o estado de leitor efetivo não é simplesmente uma questão de escolha ou gosto pessoal, como se costuma acreditar. Por trás do retrato de um país apresentado como uma nação que não lê (Retratos da Leitura no Brasil, 2012), mas que não investe na Educação para universalizar as oportunidades de aprendizagem da leitura, estão cinco séculos de história que explicam a permanência desse estado de leitura rarefeita e desigual da população brasileira (LAJOLO; ZILBERMAN, 1991).

Penso, pois, que se professores e bibliotecários apenas reproduzirem o discurso corrente sobre a leitura, cheio de equívocos e distorções, dificilmente a escola e a biblioteca pública se desvincularão da visão meramente operacional e técnico-administrativa do processo cultural e do ato de ler, visão essa que aceita a leitura como mero exercício de transferência de informação ou, no melhor dos casos, uma leitura que se esgota na decodificação, sem, contudo, provocar no sujeito leitor a capacidade de repensar a si mesmo e a sua realidade. Infelizmente, muitos mediadores da leitura se limitam, por ingenuidade ou formação precária, a estimular na criança e no jovem uma leitura que não é viagem, não é nutrição do espírito como promete a propaganda, mas experiências que não provocam espanto, nem reflexão, esvaziadas de qualquer potencial emancipatório, que espelham e reproduzem os valores da sociedade capitalista que se sustenta sobre as desigualdades entre as diferentes classes sociais. 
Por certo, é preciso atenção para o fato de que a formação de um quadro vivo de leitores, de leitores críticos, não se dá no vazio ou por acaso, como bem lembra em seus textos o pesquisador Edmir Perrotti (1990), uma vez que a leitura não é um ato natural, mas cultural e historicamente demarcado. O gesto aparentemente banal e corriqueiro de abrir as páginas de um livro subentende a existência anterior de uma complexa trama de relações sociais e políticas. De fato, a especificidade da leitura, reforça outro estudioso da leitura, está na inclusão do sujeito num determinado modo de cultura, ou seja, na compreensão da leitura como uma prática social circunstanciada, favorecendo o alargamento do espírito e das possibilidades de atuação e intervenção na sociedade. (BRITTO, 2012, p. 48) Nesse sentido, defendo a ideia de que a biblioteca pública enquanto instituição social ligada à leitura e posta a serviço da comunidade precisa ser reinventada em cada época e lugar. Em outras palavras, é preciso que a biblioteca pública brasileira seja reinventada para além dos modelos importados acriticamente; ou as interpretações ligeiras de documentos internacionais como, por exemplo, o Manifesto da UNESCO e outros documentos que divulgam conceitos e princípios gerais referentes à biblioteca pública para o mundo inteiro. Ora, o que os países mais ricos e desenvolvidos têm feito é, justamente, fugir de padrões estereotipados e criar, reinventar, é a palavra, modelos locais de bibliotecas públicas e escolares.

$\mathrm{Na}$ verdade, não precisamos citar os países ditos mais adiantados. O exemplo mais digno, atualmente, é o da Colômbia. Após a $2^{a}$ versão do Manifesto da UNESCO, de 1972, que sintetizava como funções da biblioteca pública a Educação, a Cultura, o Lazer e a Informação, as lideranças educacionais e bibliotecários da Colômbia iniciaram um movimento de estudos e apropriações daqueles princípios construindo um modelo de biblioteca publica que realmente correspondesse às necessidades e aos anseios da sociedade colombiana. Hoje (mesmo sob o risco da supervalorização propagandística por parte do governo) as bibliotecas colombianas são modelo de instituição social realmente preocupada com a reconstrução de um país gravemente marcado pelas feridas que afetam todos os países da nossa Latinoamerica.

Assim, acreditar no valor de transformação da leitura é, também, desconfiar das soluções imediatistas e pragmáticas que orientam a promoção da leitura em muitas escolas e bibliotecas, na crença de que o não-leitor pode ser facilmente convertido à prática da leitura em função de certas técnicas de animação cultural, desde que professores e bibliotecários sejam treinados nessas mesmas técnicas. Vista sob esse prisma a leitura transforma-se em mero comportamento a ser estimulado pelo profissional encarregado de dar maior visibilidade à atuação da biblioteca, sem se preocupar, em primeiro lugar, com o sentido que tal prática possa vir a ter para o sujeito leitor e para a sociedade à qual pertence. A bibliotecária colombiana Silvia Castrillón, em suas numerosas reflexões sobre a biblioteca pública no século XXI diz não acreditar que seja possível viver no mundo atual, sendo bibliotecário ou educador, sem 
assumir um compromisso com o seu país, com a mudança, com a busca de um mundo melhor através da democratização da leitura e do conhecimento. Nesse sentido, a biblioteca pública brasileira, não pode continuar se contentando com um plano mínimo de trabalho, apenas voltado para o público dos já iniciados, que chegam espontaneamente à biblioteca, e o outro público cativo, o dos obrigados pela tarefa escolar. A biblioteca pública, hoje, ao invés de se retrair diante da tendência à busca da informação a partir do espaço privado (para quem pode pagar por essa escolha) precisa, ao contrário, se construir e/ou se solidificar como espaço do encontro, do compartilhamento e do debate entre pessoas de diferentes níveis sociais e faixas etárias. Um espaço, enfim, numa época de exacerbada e perigosa individualidade, que abrigue a alteridade e a diversidade cultural.

Enfim, a caminhada em direção à leitura começa, como outras aquisições mentais e culturais do indivíduo, já nos primeiros anos de vida, e cada leitor fará esse percurso de maneira única, embora dentro de uma dada realidade social. Sem pretender traduzir esse processo num modelo fechado e estanque, acredito que ser leitor, ser leitor crítico, produzir sentidos através da leitura se dá mais facilmente quando o ato de ler se faz desejado, é compartilhado e enseja a recriação. Dito de outra maneira, o ato de ler pode ser desejado, mesmo quando é proposto pela autoridade dos pais ou da escola, se o valor dessa prática perpassa as ações da comunidade familiar e escolar, sendo apropriado também pelo leitor em formação. Buscar uma maior compreensão do mundo através da leitura nos seus variados suportes, e compartilhar essa busca com os outros membros do grupo, em família, na escola e na biblioteca pública tem se mostrado o melhor modelo de pedagogia da leitura. Dizer, ainda, que a leitura deve ser prazerosa, é um risco que corro aqui, sabedora dos muitos equívocos praticados nas escolas e bibliotecas a partir de uma concepção ligeira do que seja a leitura lúdica. Mas, o ato de ler que dá um prazer profundo, conforme o compreendo, não é o prazer fácil, epidérmico, que advém da leitura simplista do texto, leitura plana, que se esgota mal se fecha a última página do livro. Penso, ao contrário, no prazer da descoberta que vem após o mergulho fundo numa obra que nos desafia, do qual saímos renovados, do enfrentamento de um texto dito difícil, que vamos entendendo com esforço e que, ao final, nos faz subir a um outro patamar de compreensão do homem e do mundo.

\section{Considerações finais}

Para terminar, gostaria de lembrar a psicolinguista Emilia Ferreiro para reforçar a ideia de que o que se espera do leitor é determinado socialmente, numa certa época ou cultura. De fato, como têm mostrado os estudiosos da História da Leitura, as formas de leitura no século XVIII eram diferentes dos modos de ler do homem no século $X X$, que também diferem do modo de ler hoje, na sociedade do conhecimento. Na era da leitura digital, que traz implícitas as ideias de velocidade e seletividade, não é apenas o desejo de ler ou de não ler textos impressos que se 
alterou!É também o MODO de ler que já é diferente entre os que já nasceram sob o signo da era digital. Da produção do texto à recepção, os caminhos se encurtam e o leitor interage cada vez mais diretamente com o texto, algumas vezes durante o próprio ato de criação pelo autor.

São mudanças recentes e não temos ainda um distanciamento que nos permita avaliar de forma precisa o impacto desses novos comportamentos de leitura em relação ao processo educativo e existencial na sua totalidade. O que já se mostra como característica do novo tempo é que o aumento das possibilidades de circulação de textos em diferentes formatos, ao invés de afastar os jovens da leitura pode estar contribuindo para formar novos leitores, ou novos tipos de leitores, ou ainda, novos leitores de novos textos a partir da redefinição das conexões entre lar/mundo/leitura, escola/mundo/leitura, biblioteca/mundo/leitura. Na perspectiva desses cenários mutantes concluo aqui, acatando a sugestão do título da Mesa, que a leitura, no papel ou nas telas, continua, sim, sendo, potencialmente, uma forma de pertencimento crítico ao mundo (BRITTO, 2012, p. 48), dependendo das circunstâncias sócio-históricas em que se realize. Ou, em sintonia com o pensamento de Paulo Freire, continuo desejando e, a meu modo, lutando, para que a leitura mais sirva ao indivíduo leitor como um impulso de emancipação e transformação, do que um elemento a mais de domesticação e alienação.

É o que eu queria dizer aqui, neste fórum de discussão sobre a Biblioteca pública, a educação e a leitura.

Obrigada.

\section{Referências}

ADORNO, Theodor. Teoria da Semicultura. Tradução de Newton Ramos de Oliveira et al. Educação e Sociedade, ano XVII, n. 56, p. 388-411, dez. 1996.

ARRIGUCCI JUNIOR, Davi. Leitura: entre o fascínio e o pensamento. Disponível em: <http://www.crmariocovas.sp.gov.br/lei_a.php?t=004>. Acesso em: 14 jan. 2014.

BOURDIEU, Pierre. Sobre a televisão. Rio de Janeiro: Zahar, 1997.

BRITTO, Luiz Percival. Inquietudes e Desacordos: a leitura além do óbvio. Campinas: Mercado de Letras, 2012.

CASTRILLÓN, Silvia. O direito de ler e escrever. São Paulo: Pulo do Gato, 2012.

COLOMER, Teresa. Andar entre livros: a leitura literária na escola. São Paulo: Global, 2007.

FREIRE, Paulo. Pedagogia do oprimido. Rio de janeiro: Paz e Terra, 1983.

INSTITUTO PRÓ-LIVRO. Retratos da leitura no Brasil. 3. ed. 2012.

LAJOJO, MARIZA; ZILBERMAN, Regina. A leitura rarefeita; leitura e livro no Brasil. São Paulo: Ática, 1991. 
PERROTTI, Edmir. Confinamento cultural, infância e leitura. São Paulo: Summus, 1990.

ROSS, Catherine Sheldrick. The metaphors of reading. The Journal of Library History, Philosophy, and Comparative Librarianship, v. 22, n. 2, p. 147-163, 1987. 